\title{
Fast measurement by infrared spectroscopy as support to woody biofuels quality determination
}

\author{
Daniele Duca, Andrea Pizzi, Manuela Mancini, Giorgio Rossini, Chiara Mengarelli, \\ Alessio Ilari, Giulia Lucesoli, Giuseppe Toscano, Ester Foppa Pedretti \\ Department of Agricultural, Food and Environmental Sciences, Marche Polytechnic \\ University, Ancona, Italy
}

\begin{abstract}
The increase in the demand for energy supply during the past few decades has brought and will bring to a growth in the utilisation of renewable resources, in particular of solid biomasses. Considering the variability in the properties of biomass and the globalisation of the timber market, a chemical and physical characterisation is essential to determine the biomass quality.

The specific international standards on solid biofuels (ISO 17225 series) describe proper specification and classification of wood chip and pellet, to ensure appropriate quality. Moreover, standard requires information about origin and source of the biomass, normally only to be declared by the producers. In order to fulfill the requirements for the biomass quality, the origin and the source should be assessed, even if currently is hard to determine, in particular on milled or densified biomass. Infrared spectroscopy can provide information on the biomass at the chemical level, directly linked also to its origin and source. This technique is fast and not destructive thus suitable also for online monitoring along the biofuel production chain. In this study, 60 samples belonging to 8 different species were collected and
\end{abstract}

Correspondence: Daniele Duca, Department of Agricultural, Food and Environmental Sciences, Marche Polytechnic University, via Brecce Bianche 12,60131 Ancona, Italy.

Tel.: +39.071.2204297 - Fax: +39.071 .2204167 .

E-mail: d.duca@univpm.it

Key words: Pellet; wood chip; standardisation; characterisation; biomass source.

Acknowledgements: the authors would like to thank Margaritelli Group, Listone Giordano trademark holder, for the support in the development of this study.

Conference presentation: AIIA 2015 Conference, Naples, Italy.

Received for publication: 14 July 2015.

Accepted for publication: 27 September 2015.

CC Copyright D. Duca et al., 2016

Licensee PAGEPress, Italy

Journal of Agricultural Engineering 2016; XLVII:499

doi:10.4081/jae.2016.499

This article is distributed under the terms of the Creative Commons Attribution Noncommercial License (by-nc 4.0) which permits any noncommercial use, distribution, and reproduction in any medium, provided the original author(s) and source are credited. related spectra were acquired using a Fourier transform infrared (IR) spectrometer equipped with a module for solid analysis and analysed by principal component analysis. The results obtained show that the method is very efficient in the identification between coniferous and deciduous wood (99\% confidence level) and good results were obtained in the recognition of coniferous/deciduous mixtures, too. Nevertheless, some clear differences have been also noted among intra-class grouping, but additional tests should be carried out.

This technique can provide useful information to solid biofuel stakeholders about wood quality and origin, important especially for sustainability issues. Further work will be oriented to the development of IR methodologies for the fast measurement of other important biomass parameters (e.g., ash content, high calorific value, nitrogen content, etc.).

\section{Introduction}

Considering the continuous increase in energy demand (Casal $e t$ al., 2010) at global level, during the next years the energy production is expected to grow (González et al., 2015). For this reason it is important to ensure the supply of reliable and affordable energy and to achieve a low-carbon, high-efficiency and sustainable energy system.

In order to decrease the levels of greenhouse gases in our atmosphere it is fundamental to increase the contribution of renewable energy to our energy supply (IEA, 2004). In that respect, European public policies have set the target of $20 \%$ for the share of renewable sources in energy consumption in the EU by 2020 .

Since 2004, the share of renewable sources in gross final consumption of energy grew significantly in all European Member States, with thirteen Member States having at least doubled their share of renewables over the last 10 years (EUROSTAT, 2015). Biomass, a key renewable energy source, contributed approximately $9.9 \%$ to the EU's renewable electricity in 2013 (EUROSTAT, 2015).

Considering the increase in the use of solid biofuels, a greater control of biomass to ensure its quality is needed. Some biofuels are relatively homogeneous, i.e., wood pellets (Toscano et al., 2013; Duca et al., 2014), while others like woodchips are rather heterogeneous because of the presence of bark and other contaminants (Spinelli $e t$ al., 2011).

In recent years CEN/TC 335 has established a number of standards relating to solid biofuel quality including woody and non-woody material to ensure biomass quality both for industrial use and commercial and residential application (CEN/TC 335, 2014).

According to the CEN standards, biomasses have to respect specified limits for a number of quality parameters to make sure the efficient operation of industrial and small-scale boilers. Quality is determined not only by chemical-physical parameters, but also by quality attributes such as origin and source to be displayed on the labels of 
the product. Unfortunately, conventional wet chemistry analysis is time-consuming, labour-intensive and expensive, all of which hinder at-line or online operation (Liu et al., 2010). Infrared spectroscopy returns results in short time and at a reduced cost, thus can permit a best control on the market by the producers and distributors of the biofuel and the operators involved in the quality control. Within this context near infrared spectroscopy is playing an important role in the biofuel and bioenergy sector for the prediction of chemical characteristics (Lestander et al., 2009; Fagan et al., 2011) and quality attributes of biomass (Chen et al., 2010; Santoni et al., 2015).

Prediction of the origin and source using infrared spectroscopy would allow biomass producers and suppliers to guarantee that the product fulfils the requirements for the biomass quality, especially on milled or densified biomass currently hard to determine and only declared by the producers with few practical possibilities to verify these claims.

Taking into account the above considerations, the purpose of this study is to identify spectral differences between hardwood and softwood samples by means of Fourier transform infrared spectrometer (FT-IR) and principal component analysis (PCA) (Bergman et al., 2005). For this purpose, the spectra of 60 wood samples were used as training set. Furthermore, the PCA model was tested by analysing six mixtures of different amount of hardwood and softwood.

\section{Materials and methods}

\section{Sample preparation}

In this study, 30 hardwoods and 30 softwoods, reported in Table 1, have been collected and analysed. The selected wood species are widespread and common in Europe for pellet production. The samples were obtained from whole pieces of wood with well-known origin, like beams or boards from sawmills and debarked tree log disks wood slices. All the samples were initially reduced in smaller pieces and subsequently were ground by means of a cutting mill (mod. SM 2000; Retsch $\mathrm{GmbH}$, Haan, Germany). The material was sieved and the particles size under $0.25 \mathrm{~mm}$ was selected for IR analysis. The samples were stored in plastic containers until the analysis.

Some mixtures between hardwood and softwood were prepared and analysed in the same way as samples in order to test the ability of the multivariate model to distinguish the mixtures from the individual constituents in pure ground wood products.

For the preparation of the mixtures the most common European species for the production of woody pellets in Europe have been used, i.e., beech, fir and pine. In order to increase the representativeness of the material and to simulate the industrial conditions, 10 samples of the same species were mixed together in equal quantities to obtain an average sample. The average samples were then mixed in the proportions indicated in Table 2 to form the 6 mixtures used in this study.

\section{Fourier transform-infrared-attenuated total reflectance analysis}

Mid infrared spectra were collected for all woody samples by means of a Fourier transform infrared spectrometer (FT-IR mod. Nicolet iS 10; Thermo Fisher Scientific, Inc., Waltham, MA, USA) equipped with a ZnSe single reflection attenuated total reflectance accessory (mod. Smart iTR; Thermo Fisher Scientific, Inc.). For each analysis a small amount of milled sample was pressed onto the crystal using a high pressure tower and its infrared spectra acquired with the following settings: wave number range of $4000 \div 600 \mathrm{~cm}^{-1}$; 64 scans per sample; spectral resolution of $4 \mathrm{~cm}^{-1}$. In order to exclude signals, which are not associated to the sample (e.g., environment), an infrared spectrum without sample (blank spectrum) was acquired before each analysis. All samples were analysed in triplicate.

\section{Data pre-treatment and principal component analysis}

All infrared spectra were pre-treated before performing PCA. The signal pre-treatment is useful to better show the spectral differences between hardwood and softwood. PCA is one of several multivariate chemometric methods able to extract information from noisy data; in this study it was performed for the evaluation of spectral data and for the discrimination of the two classes of wood. All the pre-treatment operations were performed by The Unscrambler ${ }^{\circledR}$ (ver. 9.7; Camo Process AS, 0slo, Norway). As a first step, the fingerprint region that contained the most spectral information was selected for subsequent elaboration, i.e., the wavenumber range between $650 \mathrm{~cm}^{-1}$ up to 1850 $\mathrm{cm}^{-1}$.

Afterwards, standard normal variate was performed to reduce the variations caused by scattering effects and first derivatives (second polynomial order, 13 smoothing points with Savitzky-Golay) were calculated in order to enhance spectral differences. As last step, before the chemometric processing, the three replicates of each sample were averaged in one representative pre-processed spectrum.

PCA was performed by means of Matlab (ver. 7.10.0; The MathWorks, Inc., Natick, MA, USA) on the data matrix of wood samples resulting from the pre-treatment process. The data were mean centred before computation. For each of the two groups, i.e., hardwood and softwood, an error ellipse was calculated at a specific level of significance ( $99 \%$ confidence level). Loading plot of the PC1 was assessed to identify the compounds associated to the hardwood and softwood discrimination. Finally, the spectra of the mixtures were projected on PCs space using the loadings calculated in the PCA of wood samples. A further elaboration of the PCA results has shown also a good performance in wood species identification.

Table 1. Number of samples divided by type of species.

\begin{tabular}{lcc} 
Hardwood & $(\mathrm{n}=30)$ & Softwood \\
Sessile oak (Quercus petraea) & 10 & Larch (Larix decidua) \\
Beech (Fagus sylvatica) & 10 & Fir (Abies spp.) \\
\hline Ash (Fraxinus excelsior) & 3 & Pine (Pinus spp.) \\
Sycamore maple (Acer pseudoplatanus) & 4 & 11 \\
\hline Sugar maple (Acer saccharum) & 3 & \\
\hline
\end{tabular}




\section{Results and discussion}

\section{Spectra analysis}

The FT-IR spectra of 30 softwoods and 30 hardwoods are shown in Figure 1. Although the spectra could seem similar graphically, there are some evident spectral differences between hardwood and softwood groups, as highlighted in Figure 1. These differences are obviously less evident in mixture of both groups.

PCA can exploit these differences to identify which group the sample belongs to or the component amounts in a mixture. For this reason PCA could be a useful analytical tool for wood and pellet industries for monitoring, processing control and logistic issues.

\section{Principal component analysis}

The scree plot (Figure 2) shows that the two first PCs together account for $86.3 \%$ (PC1: 78.6\%; PC2: 7.7\%) of the total initial variability, considering also PC3 (4.7\%) the value reaches $91.0 \%$. Therefore, the following elaborations take into account the three first PCs.

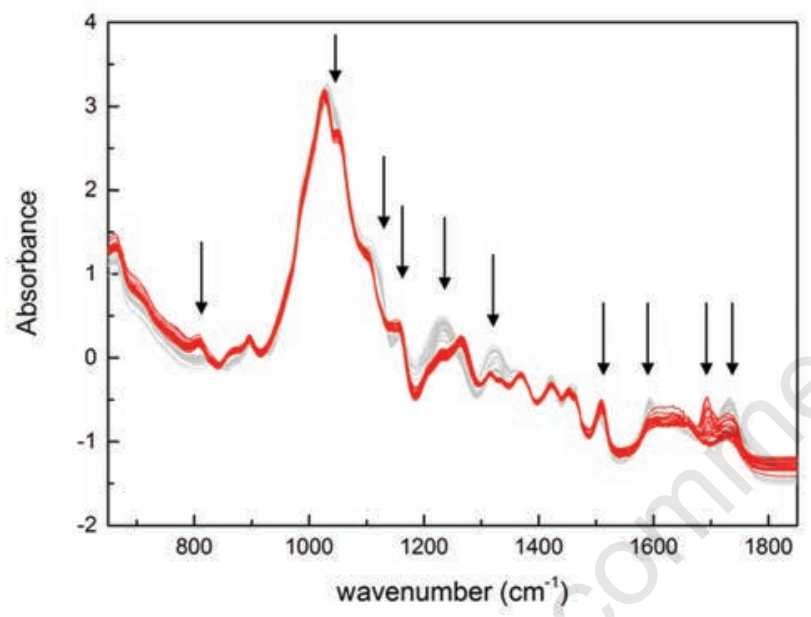

Figure 3 presents the scores of the three first PCs: as evident there is a clear separation between the two groups along the PC1. Hardwoods have positive PC1 scores, while softwoods have negative PC1 scores. Hardwood and softwood groups are significantly separated as shown by 99\% confidence limits, highlighted as grey ellipsoids in Figure 3.

The projections of the six mixtures on the three first PCs space are

Table 2. Proportions of hardwood/softwood mixtures.

\begin{tabular}{lccc} 
Mixture & Beech & Fir & Pine \\
BF 1 & 25 & 75 & - \\
BF 2 & 50 & 50 & - \\
\hline BF 3 & 75 & 25 & - \\
BP 1 & 25 & - & 75 \\
\hline BP 2 & 50 & - & 50 \\
BP 3 & 75 & - & 25 \\
\hline
\end{tabular}

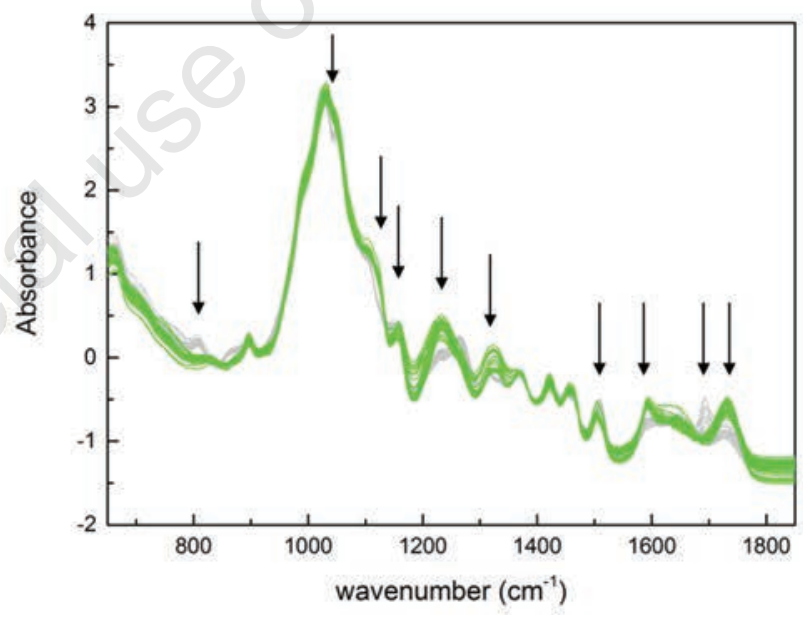

Figure 1. Spectra of softwood (red line on the left, $\mathrm{n}=30$ ) and hardwood (green line on the right, $\mathrm{n}=30$ ).

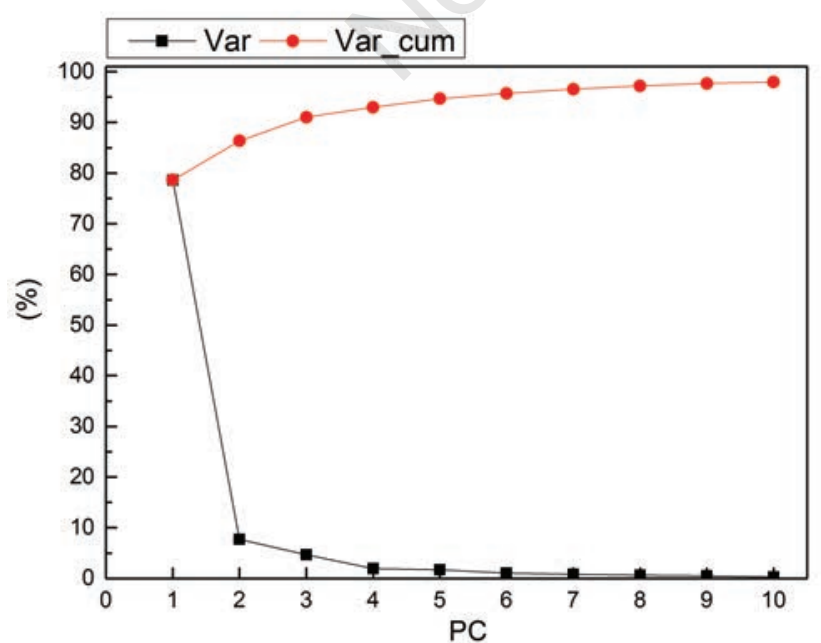

Figure 2. Scree plot of principal component (PC) analysis.

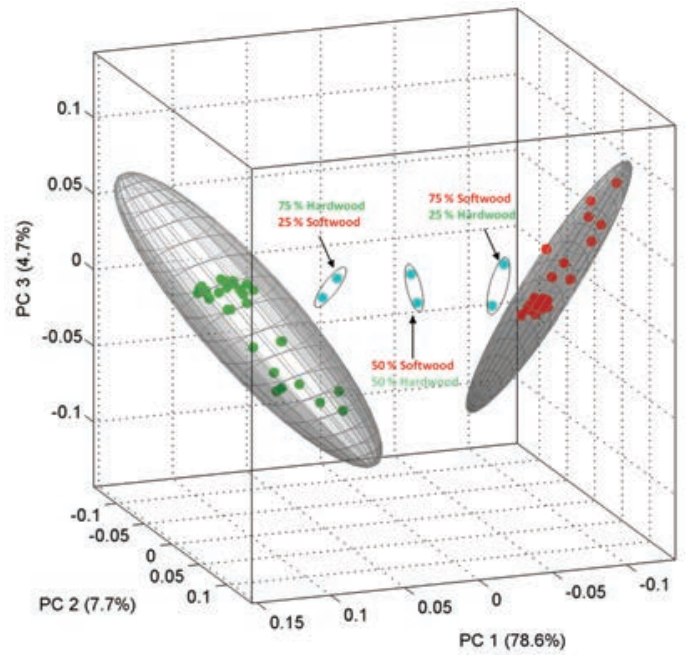

Figure 3. Score plot of the three first principal components (PC). Green dots: hardwood; red dots: softwood; blue dots: mixture. 
clearly positioned outside the ellipsoids. In addition, the distances from the groups are in line with the mixture percentages: BF1 and BP1 are placed in the left side of the plot near the softwood ellipsoid, while BF3 and BP3 are placed in the right side near the hardwood ellipsoid. BF2 and BP2 are positioned in the middle as expected, highlighting the suitability of the method. It is evident that the methodology is efficient in identifying mixture from pure wood and has a good potential for quantitative purposes also at low concentrations.

More detailed information at the qualitative level about wood species can be obtained. In Figure 4 is reported the result of intra-class grouping, where samples belonging to the same species have similar scores. This behaviour is more evident for some species than others. Sessile oak is clearly divided from the other deciduous species. The two species of maple can be clustered in the same group. Evident is also the division between pine and fir and between sessile oak and beech.
Instead, small groups of samples, i.e., larch and ash, are problematic to discriminate probably because of the low number of samples. Even if the recognition of the species was not the principal aim of this study, some very good results have been achieved and could be further investigated in order to be exploited in industry applications.

In Figure 5 the loading plot of PC1 has been reported with the indication of the most relevant wavenumbers. In Table 3 the most relevant wavenumbers associated to the differences between hardwoods and softwoods have been reported. The most relevant compounds responsible to the discrimination are lignin and hemicellulose, which are effectively different in chemical composition between hardwood and softwood. In more detail softwood lignin is mainly (<98\%) composed of guaiacyl-units (Feldman, 1985), while hardwood one is composed by guaiacyl/syringil units in variable rates. Hemicelluloses are mainly composed by $80-90 \%$ of $4-0$-methylglucoronoxylan in hardwoods, while

Table 3. Main infrared absorption bands found in PC1 responsible for hardwood and softwood discrimination.

\begin{tabular}{|c|c|c|c|c|}
\hline Peak number & Wavenumber $\left(\mathrm{cm}^{-1}\right)$ & Assignment & Compound & Reference \\
\hline 1 & 806 & Glucomannan & $\mathrm{H}$ & (Schwanninger et al., 2004; Deka et al., 2008) $806 \mathrm{~cm}^{-1}$ \\
\hline 2 & 1042 & (s) $\mathrm{C}-\mathrm{C}$ and (s) $\mathrm{C}-\mathrm{O}$ & - & (Popescu et al., 2009) $1040 \mathrm{~cm}^{-1}$ \\
\hline 3 & 1122 & (b) $\mathrm{C}$-H in plane in the syringyl monomer & $\mathrm{L}$ & (Pandey and Pitman, 2003) $1122 \mathrm{~cm}^{-1}$ \\
\hline 4 & 1143 & (b) aromatic C-H in plane of guaiacyl units & L & (Schwanninger et al., 2004) $1140 \mathrm{~cm}^{-1}$ \\
\hline 5 & 1235 & $\begin{array}{l}\text { Syringyl ring breathing with (s) C-O, (s) } \\
\text { C-C stretching, (b) OH in plane }\end{array}$ & $\mathrm{L}, \mathrm{C}$ & $\begin{array}{l}\text { (Evans, 1991; Popescu et al., 2009) } 1234 \mathrm{~cm}^{-1} \\
\text { (Reyes et al., 2013) } 1233 \mathrm{~cm}^{-1} \\
\text { (Emandi et al., 2011) } 1226-1234 \mathrm{~cm}^{-1}\end{array}$ \\
\hline 6 & 1328 & $\begin{array}{l}\text { Cl-O syringyl derivates plus guaiacyl } \\
\text { (characteristic of hardwoods) } \\
\text { and C-H vibration in cellulose }\end{array}$ & $\mathrm{L}, \mathrm{C}$ & $\begin{array}{l}\text { (Emandi et al., 2011) } 1320-1328 \mathrm{~cm}^{-1} \\
\text { (Pandey and Pitman, 2004) } 1328 \mathrm{~cm}^{-1} \\
\text { (Faix, 1991) } 1330 \mathrm{~cm}^{-1}\end{array}$ \\
\hline 7 & 1512 & Specific band of aromatic skeletal vibrations & L & $\begin{array}{l}\text { (Popescu et al., 2009) } 1510 \mathrm{~cm}^{-1} \\
\text { (Schwanninger et al., 2004) } 1515-1505 \mathrm{~cm}^{-1} \\
\text { (Emandi et al., 2011) } 1510-1501 \mathrm{~cm}^{-1}\end{array}$ \\
\hline 8 & 1593 & $\begin{array}{l}\text { (s) } \mathrm{C}=\mathrm{C} \text { of the aromatic ring (syringyl), } \\
\text { (s) } \mathrm{C}=\mathrm{O} \text {, (b) } \mathrm{CH}\end{array}$ & L & (Popescu et al., 2009) $1594 \mathrm{~cm}^{-1}$ \\
\hline 9 & 1693 & $\begin{array}{l}\mathrm{C}=0 \text { stretching vibrations of unsaturated } \\
\text { acids and ketones (resin acids) }\end{array}$ & $\mathrm{E}$ & $\begin{array}{l}\text { (Mamleeva et al., 2009) } 1690 \mathrm{~cm}^{-1} \\
\text { (Nuopponen et al., 2003; Rautkari et al., 2010) } 1697 \mathrm{~cm}^{-1}\end{array}$ \\
\hline 10 & 1734 & $\begin{array}{l}\text { (s) Unconjugated } \mathrm{C}=0 \text { in ketones, } \\
\text { carbonyls and ester groups in xylans, } \\
\text { well defined in hardwood respect to softwood }\end{array}$ & d & $\begin{array}{l}\text { (Chen et al., 2010) } 1739 \mathrm{~cm}^{-1} \\
\text { (Pandey and Pitman, 2003) } 1738 / 1734 \mathrm{~cm}^{-1} \\
\text { (Emandi et al., 2011) } 1724-1736 \mathrm{~cm}^{-1}\end{array}$ \\
\hline
\end{tabular}

(s), stretching; (b), bending; H, hemicellulose; C, cellulose; L, lignin; E, extractives.

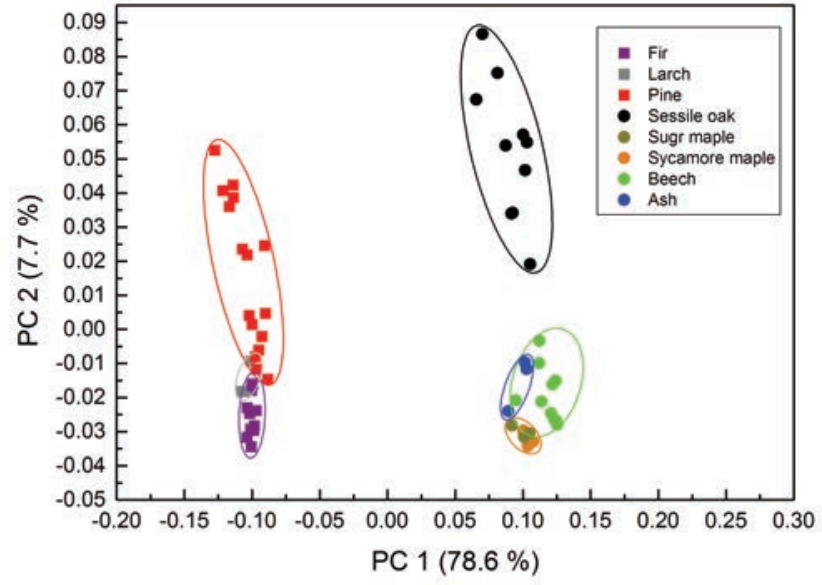

Figure 4. Score plot of the two first principal components (PC).

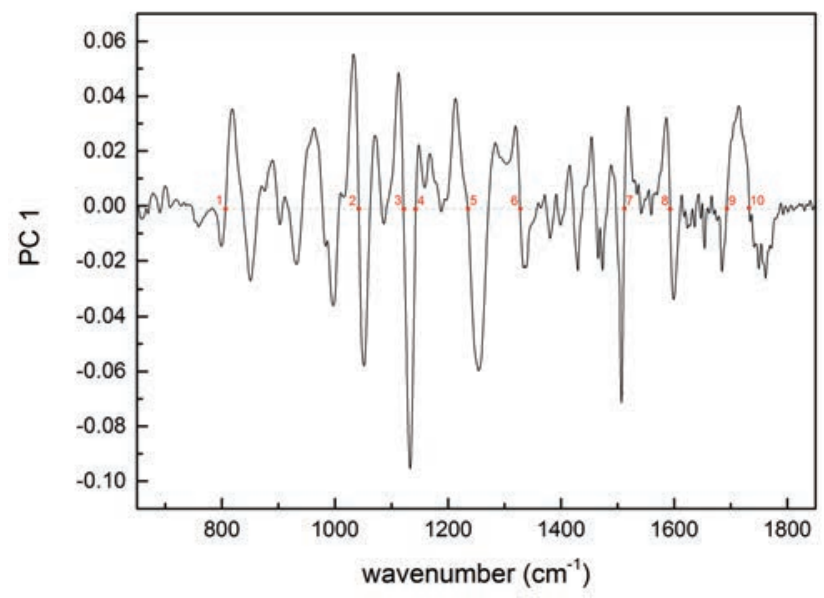

Figure 5. Loading plot of principal component 1 (PC1). 
$60-70 \%$ glucomannans and $15-30 \%$ arabinogalactan are the main constituents in the softwood (Toscano et al., 2015).

\section{Conclusions}

This study clearly indicates that infrared spectroscopy associated with multivariate analysis can effectively discriminate wood samples between hardwood, softwood and mixtures. For this reason, the method could be a valid support to verify the compliance to biomass quality technical standard. Exploiting the chemical differences between hardwood and softwood the method is able to identify the material, mainly due to lignin and hemicellulose content. The application of this technique on the ground material employed in the pellet production process has several strong points such as fast and non-destructive analytical response, low cost of the analysis and no requirement of specialised operators. Therefore the information on the biomass quality is quickly returned. Infrared spectroscopy results to be easily implementable on production lines and allows a monitoring of the ground material both for a control of suppliers and for process tuning. Interesting practical aspects could be the mixing of hardwood and softwood in order to obtain the optimal densified product density and the control of energy consumption and efficiencies during pelletizing. Moreover, it could be used to check the conformity of the producers' declarations, e.g., softwood presence in a sample declared $100 \%$ hardwood. The method is already effective for the discrimination of hardwood, softwood and mixtures, but needs further development to enhance the information on biomass quality, both in species identification and in other quality parameters (e.g., calorific value, nitrogen content, ash content). Further studies are needed to assess the performance of this method also on more heterogeneous biofuels (e.g., woodchips).

\section{References}

Bergman P.C.A., Boersma A.R., Zwart R.W.R., Kiel J.H.A. 2005. Torrefaction for biomass co-firing in existing coal-fired power stations “BIOCOAL". ECN Report ECN-C-05-013. Energy research Centre of the Netherlands (ECN), Petten, The Netherlands.

Casal M.D., Gil M.V., Pevida C., Rubiera F., Pis J.J. 2010. Influence of storage time on the quality and combustion behaviour of pine woodchips. Energy 35:3066-71.

CEN/TC 335 (European Committee for Standardisation). 2014. EN ISO 17225-1 - Fuel specifications and classes. Brussels, Belgium.

Chen H., Ferrari C., Angiuli M., Yao J., Raspi C., Bramanti E. 2010. Qualitative and quantitative analysis of wood samples by Fourier transform infrared spectroscopy and multivariate analysis. Carbohydrate Polymers 82:772-8.

Deka M., Petri M. 2008. Photo-degradation of water borne acrylic coated modified and non-modified wood during artificial light exposure. BioResour. 3:346-62.

Duca D., Riva G., Foppa Pedretti E., Toscano G. 2014. Wood pellet quality with respect to EN 14961-2 standard and certifications. Fuel 135:9-14.

Emandi A., Vasiliu C. I., Budrugeac P., Stamatin I. 2011. Quantitative investigation of wood composition by integrated FT-IR and thermogravimetric methods. Cell. Chem. Technology 45:579-84.

EUROSTAT. 2015. Share of renewables in energy consumption up to $15 \%$ in the EU in 2013. Available from: http//ec.europa.eu/eurostat/documents/2995521/6734513/8-10032015-AP-EN.pdfAccessed: March 2015.

Evans P.A. 1991. Differentiating "hard" from "soft" woods using Fourier transform infrared and Fourier transform spectroscopy. Spectrochim.
Acta Part A Mol. Spectroscopy 47:1441-7.

Fagan C.C., Everard C.D., McDonnell K. 2011. Prediction of moisture, calorific value, ash and carbon content of two dedicated bioenergy crops using near-infrared spectroscopy. Bioresour. Technol. 102:5200-6.

Faix 0. 1991. Classification of lignins from different botanical origins by FT-IR Spectroscopy. Holzforschung Int. J. Biol. Chem. Phys. Technol. Wood 45:21-8.

Feldman D. 1985. Wood-chemistry, ultrastructure, reactions, by D. Fengel and G. Wegener, Walter de Gruyter, Berlin and New York, 1984, 613 pp. Price: 245 DM. J. Polymer Sci. Polymer Lett. Ed. 23:601-2.

González A., Riba J.-R., Puig R., Navarro P. 2015. Review of micro- and small-scale technologies to produce electricity and heat from Mediterranean forests wood chips. Renew. Sustain. Energy Rev. 43:143-55.

IEA. 2004. World Energy Outlook 2004. IEA Publications, Paris, France.

Lestander T.A., Johnsson B., Grothage M. 2009. NIR techniques create added values for the pellet and biofuel industry. Bioresour. Technol. 100:1589-94.

Liu L., Ye X.P., Womac A.R., Sokhansanj S. 2010. Variability of biomass chemical composition and rapid analysis using FT-NIR techniques. Carbohydrate Polymers 81:820-9.

Mamleeva N.A., Autlov S.A., Bazarnova N.Y.G., Lunin V.V. 2009. Delignification of softwood by ozonation. Pure Appl. Chem. 81:208191.

Nuopponen M., Vuorinen T., Jämsä S., Viitaniemi P. 2003. The effects of a heat treatment on the behaviour of extractives in softwood studied by FTIR spectroscopic methods. Wood Sci. Technol. 37:109-15.

Pandey K.K., Pitman A.J. 2003. FTIR studies of the changes in wood chemistry following decay by brown-rot and white-rot fungi. Int. Biodeterior. Biodegrad. 52:151-60.

Pandey K.K., Pitman A.J. 2004. Examination of the lignin content in a softwood and a hardwood decayed by a brown-rot fungus with the acetyl bromide method and Fourier transform infrared spectroscopy. J. Polymer Sci. Part A Polymer Chem. 42:2340-6.

Popescu C.-M., Singurel G., Popescu M.-C., Vasile C., Argyropoulos D.S., Willför S. 2009. Vibrational spectroscopy and X-ray diffraction methods to establish the differences between hardwood and softwood. Carbohydrate Polymers 77:851-7.

Rautkari L., Properzi M., Pichelin F., Hughes M. 2010. Properties and setrecovery of surface densified Norway spruce and European beech. Wood Sci. Technol. 44:679-91.

Reyes P., Teixeira Mendonça R., Rodríguez J., Fardim P., Vega B. 2013. Characterization of the hemicellulosic fraction obtained after prehydrolysis of Pinus radiata wood chips with hot-water at different initial pH. J. Chilean Chem. Soc. 58:1614-8.

Santoni I., Callone E., Sandak A., Sandak J., Dirè S. 2015. Solid state NMR and IR characterization of wood polymer structure in relation to tree provenance. Carbohydrate Polymers 117:710-21.

Schwanninger M., Rodrigues J.C., Pereira H., Hinterstoisser B. 2004. Effects of short-time vibratory ball milling on the shape of FT-IR spectra of wood and cellulose. Vibrat. Spectroscopy 36:23-40.

Spinelli R., Nati C., Sozzi L., Magagnotti N., Picchi G. 2011. Physical characterization of commercial wood chips on the Italian Energy wood market. Fuel 90:2198-202.

Toscano G., Duca D., Rossini G., Mengarelli C., Pizzi A. 2015. Identification of different woody biomass for energy purpose by means of soft independent modeling of class analogy applied to thermogravimetric analysis. Energy 83:351-7.

Toscano G., Riva G., Foppa Pedretti E., Corinaldesi F., Mengarelli C., Duca D. 2013. Investigation on wood pellet quality and relationship between ash content and the most important chemical elements. Biomass Bioenergy 56:317-22. 